\title{
Correction: Energetic metabolism in cardiomyocytes: molecular basis of heart ischemia and arrhythmogenesis
}

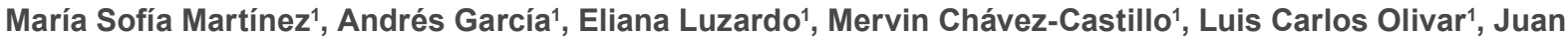 \\ Salazar ${ }^{1}$, Manuel Velasco ${ }^{2}$, Joselyn Joanna Rojas Quintero ${ }^{1,3}$, Valmore Bermúdez ${ }^{1,4}$ \\ 'Endocrine and Metabolic Diseases Research Center, School of Medicine, University of Zulia, Maracaibo 4001, Venezuela. \\ 2Department of Pharmacology, "JM Vargas" Medical School, Central University of Venezuela, Caracas 1051, Venezuela. \\ ${ }^{3}$ Division of Pulmonary and Critical Care Medicine, Brigham and Women's Hospital, Harvard Medical School, Boston, MA 02115, USA. \\ ${ }^{4}$ Advanced Frontier Studies Research Group (ALEF), Simón Bolívar University, Cúcuta 54003, Colombia.
}

Correspondence to: Dr. María Sofía Martínez, Endocrine and Metabolic Diseases Research Center, School of Medicine, University of Zulia, Maracaibo 4001, Venezuela.E-mail:mmartinez@fmed.luz.edu.ve How to cite this article: Martínez MS, García A, Luzardo E, Chávez-Castillo M, Olivar LC, Salazar J, Velasco M, Quintero JJR,
Bermúdez V. Correction: Energetic metabolism in cardiomyocytes: molecular basis of heart ischemia and arrhythmogenesis. Vessel Plus 2018;2:32. http://dx.doi.org/10.20517/2574-1209.2018.68

Received: 26 Sep 2018 First Decision: 26 Sep 2018 Revised: 11 Oct 2018 Accepted: 11 Oct 2018 Published: 23 Oct 2018

Science Editor: Mario F. L. Gaudino Copy Editor: Cui Yu Production Editor: Huan-Liang Wu

The original article was published on 28 Dec 2017.

After the publication of the article named "Energetic metabolism in cardiomyocytes: molecular basis of heart ischemia and arrhythmogenesis ${ }^{\text {s[1] }}$, we found that the article by Stanley et al.$^{[2]}$ was unwisely omitted from the fourth paragraph of the section titled "Fuel for myocardial contraction: the role of macromolecules". This reference should be cited in the first, third and fourth sentences of this section, namely "The metabolic machinery of the heart utilizes oxygen up to $80 \%-90 \%$ of the maximum capacity of the electron transport chain; however, at a resting state, the heart operates at only $15 \%-25 \%$ of its maximum oxidative capacity", "Cardiomyocytes show an elevated rate of ATP hydrolysis, which is strongly linked to oxidative phosphorylation. Because under non-ischemic conditions, over 95\% of these cells' ATP is produced in this process, it is indispensable in order to assure the full replenishment of the cardiomyocytes' ATP content every $10 \mathrm{~s}$, and thus maintain constant concentrations of this molecule, even under conditions of increased frequency or force of contractions" and "Of the total energy produced by ATP hydrolysis, approximately $60 \%-70 \%$ serves as fuel for contraction, while the remaining $30 \%-40 \%$ is used by the $\mathrm{Ca}^{2+}$ ATPase pumps in the smooth sarcoplasmic reticulum and other ion pumps".

\section{REFERENCES}

1. Martínez MS, García A, Luzardo E, Chávez-Castillo M, Olivar LC, Salazar J, Velasco M, Quintero JJR, Bermúdez V. Energetic metabolism in cardiomyocytes: molecular basis of heart ischemia and arrhythmogenesis. Vessel Plus 2017;1:230-41.

2. Stanley WC, Recchia FA, Lopaschuk GD. Myocardial substrate metabolism in the normal and failing heart. Physiol Rev 2005;85:1093129.

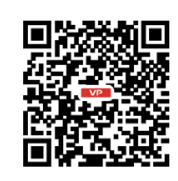

